November 2020

\title{
Metacognition, Metalinguistic Awareness, and Relevance in Language learning: A Report on an Intervention Module Project
}

Marianne Bessy

Furman University, marianne.bessy@furman.edu

Stephanie M. Knouse

Furman University, stephanie.knouse@furman.edu

Follow this and additional works at: https://digitalcommons.georgiasouthern.edu/ij-sotl

\section{Recommended Citation}

Bessy, Marianne and Knouse, Stephanie M. (2020) "Metacognition, Metalinguistic Awareness, and Relevance in Language learning: A Report on an Intervention Module Project," International Journal for the Scholarship of Teaching and Learning: Vol. 14: No. 2, Article 9.

Available at: https://doi.org/10.20429/ijsotl.2020.140209 


\title{
Metacognition, Metalinguistic Awareness, and Relevance in Language learning: A Report on an Intervention Module Project
}

\author{
Abstract \\ The purpose of this study is to examine the outcomes of a pedagogical intervention project in \\ intermediate second language (L2) French and Spanish classes at the post-secondary level. The authors \\ designed and implemented four "Language Learning Modules" (LLMs) to ascertain if these interventions \\ could enhance students' metacognitive and metalinguistic awareness and help students see the \\ relevance of studying an L2. Sixty-two students were divided evenly into a "Module" group, which received \\ the LLMs, and a "Non-Module" group, which did not receive such instruction. Analyses reveal that the \\ Module group differed from the Non-Module group in terms of how they applied metacognitive insights, \\ became more aware of the value of language learning, and found relevance in the $L 2$. The authors \\ contend that it is imperative for language educators to foster student growth in metacognitive abilities \\ and metalinguistic awareness, and to explicitly instruct students on the relevance of $L 2$ study.
}

\section{Keywords}

metacognition, metalinguistic awareness, second language learning, pedagogical intervention, global competence

\section{Creative Commons License}

c) (i) $९$

This work is licensed under a Creative Commons Attribution-Noncommercial-No Derivative Works 4.0 License. 


\title{
Metacognition, Metalinguistic Awareness, and Relevance in Language Learning: A Report on an Intervention Module Project
}

\author{
Marianne Bessy and Stephanie M. Knouse \\ Furman University \\ Received: 17 June 2019;Accepted: 4 May 2020
}

\begin{abstract}
The purpose of this study is to examine the outcomes of a pedagogical intervention project in intermediate second language (L2) French and Spanish classes at the post-secondary level. The authors designed and implemented four “Language Learning Modules" (LLMs) to ascertain if these interventions could enhance students' metacognitive and metalinguistic awareness and help students see the relevance of studying an L2. Sixty-two students were divided evenly into a "Module" group, which received the LLMs, and a "Non-Module" group, which did not receive such instruction. Analyses reveal that the Module group differed from the Non-Module group in terms of how they applied metacognitive insights, became more aware of the value of language learning, and found relevance in the L2. The authors contend that it is imperative for language educators to foster student growth in metacognitive abilities and metalinguistic awareness, and to explicitly instruct students on the relevance of L2 study.
\end{abstract}

\section{INTRODUCTION}

This SoTL study describes and discusses the implementation of a module project in the intermediate second language (L2)' classroom at a small liberal arts college in the United States. We designed this pedagogical intervention to enhance learners' metacognitive and metalinguistic skills and to increase the relevance of the language they were studying. Several factors motivated us to incorporate this module project in our instruction. First, we wanted to use data we had collected (Bessy \& Knouse, 2017) that revealed gaps in students' overall understanding of language learning in order to inform our pedagogical decisions and to enhance students' educational experience. Second, we felt it was important to find a medium that would allow students to debunk erroneous ideas of what language learning entails that are ostensibly influenced by language myths and laypeople notions. The goal was to create an overarching conversation about language learning and its benefits throughout the semester by prompting students to reflect on questions such as: What does it mean to be bilingual? Is fluency a realistic goal for my language learning journey? What are the cognitive and professional benefits of language learning? Third, we wished to answer calls to incorporate more deliberate instruction of metacognitive skills in language teaching (Thompson, 20I2) in order to improve students' self-regulating abilities.

These three goals aligned particularly well with the targeted group of students: English-dominant millennial learners enrolled in a required L2 class. Indeed, Busse and Walters (2013) have pointed out that language teaching is impacted by obstacles such as "the increasing dominance of English as a world language" which can threaten the perceived value of language learning ( $p$. 435). Another challenge faced by educators today is that of adapting to a new type of learners that display shortcomings in their level of academic responsibility and proactiveness. For instance, Buckner and Strawser (2016) have noted that "[d]espite high motivation and desire to achieve, millennials look externally for direction and approval rather than taking responsibility for their own learning" (p. 36I). In this context, it would seem beneficial for language educators to make deliberate adjustments to their pedagogies in order to make language learning more meaningful for their students. The module project discussed in this article is an attempt to adapt to these current challenges by providing English-dominant millennial learners with specific metacognitive and metalinguistic strategies to assist them with the demands of formal language learning and by increasing the relevance of the L2 in their personal academic trajectories. This SoTL investigation will present findings on how this intervention module project affected students' opinions of metacognitive strategies, metalinguistic awareness, and $\mathrm{L} 2$ relevance.

\section{LITERATURE REVIEW \\ Metacognition and metalinguistic awareness}

Enhancing learners' "metacognitive knowledge," defined by Pintrich (2002) as "knowledge about cognition in general, as well as awareness of and knowledge about one's own cognition" (p. 219), and their "metalinguistic awareness," defined by Pratt and Grieve (1984) as "the ability to think about and reflect upon the nature and functions of language" (p. 2), can result in significant gains for language learners. Thompson (20I2), in a study focusing on his intermediate Spanish L2 course, explained that "[d] eveloping students' metacognitive skills fosters student autonomy in the learning process and moves students toward higher degrees of self-direction in their careers as language learners" (p. 450). In a study focused on language listening development, Goh (2008) reported that metacognitive instruction has been proven to result in increased performance and higher levels of confidence in language learners (p. 204). Additionally, as noted by Rivera-Mills and Plonsky (2007), research has shown that "an enhanced and accurate metalinguistic awareness" fosters gains such as "more accurate [first and second language] comparisons and promotes self-correction and self-monitoring" (p. 539). Consequently, if language students who have a heightened understanding of their own processes for acquiring knowledge (metacognition) and who are able to ponder about how and why language is used (metalinguistic awareness) experience such gains, the introduction of procedures that explicitly instruct learners on metacognitive and metalinguistic strategies can positively influence language learning. Research in education and learning not specific to language instruction has also highlighted the importance of fostering such self-regulating practices as a means to enhance "self-satisfaction 
and motivation to continue to improve [students'] methods of learning" (Zimmerman, 2002, p. 66). These findings beg the question of whether or not metacognitive and metalinguistic skills can be effectively taught.

According to Brown and Larson-Hall (20I5) “[l]earners need to be able to think about their own learning: how to plan for it, how to structure it, and how to evaluate it" (p. 137). Similarly to Zimmerman (2002) who explained that "self-regulatory processes are teachable" (p. 69), Brown and Larson-Hall (20I5) further stressed that metacognition is not "a trait but rather something that can be taught" (p. I37). This call for the explicit teaching of metacognitive and metalinguistic strategies in the language classroom echoes that of many (e.g., Goh, 2008; Pintrich, 2002; Rivera-Mills \& Plonsky, 2007). Pintrich (2002) specified that clearly identifying metacognitive practices for language learners is essential in order to equip them with the tools they need to be able to discuss cognition with their peers and teacher (p. 223). Rivera-Mills and Plonsky (2007) likewise believe that "[e]ntering into a dialogue with students, either in formal learner training sessions or on more casual occasions, can help shape the strategies they use and their deeper perceptions of how languages are learned" ( $p$ 543). According to these findings, self-regulating language learning strategies fostering a shared dialogue on cognition between learners and teachers should be an integral part of language instruction today. However, a recurrent criticism of strategy training is that it has often been limited to providing learners with a list of decontextualized strategies. Tseng, Dörnyei, and Schmitt (2006) stressed that "the essential aspect of empowering learners is to set into motion the self-regulatory process rather than to offer the instruction of a set of strategies" (p. 95). There seems to be a consensus of opinion that the teaching of specific strategies is needed in order to help students take charge of their learning and address possible difficulties (Brown and Larson-Hall, 20I5, p. I4I) but that students need to be individually proactive in their language improvement journey (Tseng et al., 2006, p. 95).

Oxford's Teaching and Researching Language Learning Strategies (201 I/2013) makes a compelling case for the use of her "Strategic Self-Regulation ( $\left.S^{2} R\right)$ Model of language learning," which were designed to enable students to actively take control of their own learning (p. 7, emphasis in original). In this model, "self-regulated L2 strategies are defined as deliberate, goal-directed attempts to manage and control efforts to learn the L2" (Oxford, 20I I/20I3, p. 12, emphasis in original). According to Oxford, individuals can regulate their learning thanks to strategies, but they must be able to "choos[e] appropriate strategies for the purpose and situation and evaluat[e] the success of these strategies" (p. 14). While strategy training does not automatically equate to appropriate use of a strategy at a given time, Tseng et al. (2006) contend that learners who have "strategic knowledge of language learning" are more successful in their language acquisition than those who do not (p. 78-79).

\section{Relevance}

A number of recent studies have attempted to account for how students' beliefs can impact the language learning process. Some of these efforts have focused on determining whether increasing the relevance of the $\mathrm{L} 2$ can lead to positive outcomes. The concept of $L 2$ relevance is understood here as the degree to which the language is connected or useful to the learner. Some studies have shown that instructors can shape students' attitudes toward language learning by making the language more relevant to them. Donitsa-Schmidt, Inbar, and Shohamy (2004) investigated whether teaching spoken Arabic instead of Modern Standard Arabic in Israeli schools affected students' motivation to learn the language. Their study showed that those who were taught spoken Arabic demonstrated "more positive attitudes toward the Arabic language, its culture, and speakers, and also claimed to be more motivated to study the language" than those who were not taught spoken Arabic (p. 217). Increasing the relevance of the L2 as it relates to learners' personal circumstances therefore seems to be intimately linked to higher levels of motivation and a more positive outlook on the language.

Tackling L2 relevance from a different angle, some second language acquisition researchers have also been examining how the socio-political climate surrounding the perceived value of $L 2 s$ affects attitudes toward learning languages. Most notably, Coleman (2009), in a piece focused on language learning in the United Kingdom, investigated the link between prevailing discourses on languages and language learning motivation. For instance, looking at Eurosceptic political discourses or at the treatment of languages in the media, he hypothesized that "a growth in national insularity" had been paralleled "with a decline in foreign language learning" (p. 5). Coleman (2009) concluded by providing a list of suggested incentives that could counter this trend. For example, he urged language practitioners to deliberately "challenge the deceptive 'English-is-enough' message” as well as "disseminate good news stories celebrating the value of language skills" (p. I3). Similarly, de Bot (2007), in a piece titled "Language Teaching in a Changing World," insisted that "in order to motivate people to learn languages, those people need to know for what purpose they will use that language" and further stressed that "[a] language policy for foreign language teaching will succeed only when learners are convinced that there is a personal need for learning it" ( $p$. 274). Coleman (2009) and de Bot (2007)'s arguments, together with Donitsa-Schmidt et al. (2004)'s findings, support the idea that instructors do indeed play a key role in designing pedagogical interventions that aim to shape learners' perception of the relevance and utility value of the $L 2$.

These publications and their findings resonate particularly well with renewed efforts in the United States to create "a new normal" when it comes to language education (Moeller \& Abbott, 2018, p. 12). In their recent article tracing the American Council on the Teaching of Foreign Languages' (ACTFL) advocacy efforts throughout the years, Moeller and Abbott (2018) plead for a future where "languages are valued as an integral part of education and are viewed as necessary to the well-being of all Americans" (p. 2I). They stress that key stakeholders have an important role to play in educating learners about the benefits of proficiency in a language other than English (p. 16) and underscore the increasing need for a globally competent workforce (p. 19). Targeted pedagogical interventions aiming to explain the relevance of language learning within the context of global competence may therefore be an important piece in fostering the enhanced multilingual and multicultural milieu advocated by Moeller and Abbott.

\section{Present study}

The project at the center of this study was motivated by the findings of a longitudinal project, "The Language Learning Experiences Survey," we administered at our home institution with the goal of tracking learners' attitudes toward language learning throughout 
their college career. Specifically, we found that students considered language courses quite difficult but expected high grades, were interested in enhancing their speaking ability, and demonstrated minimal understanding of how languages could benefit them cognitively and professionally (Bessy \& Knouse, 2017). Upon reviewing these results, we were compelled to design and subsequently test the effectiveness of the "The Language Learning Modules" (LLMs), four targeted pedagogical interventions focusing on topics related to the survey findings, which are described in detail in the section below. In this study, our goal was to determine how students' self-reported metacognitive abilities and metalinguistic awareness changed over time, and whether or not they found supplementary information on L2s relevant and meaningful.

Both of the present authors were the instructors of the language courses involved in the study. As such, this investigation falls under the umbrella of SoTL and likewise should be considered as "action research," or when a practitioner intentionally researches the effectiveness of the practices she employs in her classroom. In fact, these efforts echo recent calls for action research such as that of Goh (2008) who underscored that "teacher educators can encourage teachers and teachers-in-training to have greater ownership of innovative practices. One way to do this is by engaging them in action research to explore some of the benefits of metacognitive instruction for themselves" (p. 204). Thus, the question that guided this investigation was as follows: to what extent did the LLMs impact intermediate-level L2 students' opinions of (I) metacognitive strategies, (2) metalinguistic awareness, and (3) L2 relevance?

\section{METHODS}

\section{Participants}

Participants of the present study were recruited from two intermediate French classes and two intermediate Spanish classes in spring 2018. A total of 62 Intermediate I students participated in the investigation. One of the French classes $(n=13)$ and one of the Spanish classes $(n=18)$ were designated as the experimental or "Module" group $(n=31)$. The remaining two classes in French $(n=14)$ and Spanish $(n=17)$ formed the control or "Non-Module" group $(n=31)$.

The profiles of participants in the Module and Non-Module groups were fairly similar. Exam scores from each group were compared to confirm that no major disparities were found in students' performance in the language. The Module group averaged an $83.57 \%$ on the first exam and the Non-Module group earned an average of $83.27 \%$. The Module and Non-Module groups were alike in terms of their year at the institution-the vast majority were first-year students (23/3I, Module group and $2 \mathrm{I} / 3 \mathrm{I}$, Non-Module group) —and all but 2 of the 62 students had taken the L2 at the secondary level. Only I of the 62 students had already declared the L2 as one of their majors when the beginning-of-term survey was administered. Additionally, when asked why they enrolled in the French or Spanish course, 57 out of 62 (91.9\%) students indicated that they enrolled in the class to fulfill the university's foreign language requirement. Because only 5 out of 62 (8.1\%) selected the option "I am a good [L2] student; languages come naturally to me," we determined that students with this profile might benefit from direct instruction of topics such as self-regulation, metacognition, metalinguistic awareness, and how studying languages could be relevant to them.

\section{Procedure}

All 62 students were informed at the beginning of the semester that their coursework could be considered for research and were given the opportunity to opt out at any point during the term without penalty. The researchers' Institutional Review Board approved the present investigation. At the time of the study, the researchers believed that even though the Module group would receive the treatment and the Non-Module group would not, no group had a significant or a known advantage over the other. In addition, since the intervention consisted of four activities interspersed over the term and not a comprehensive pedagogical approach (e.g., flipped classroom, content-based learning), the researchers' procedures were in line with the guidelines of ethical SoTL research (Fedoruk, 2017).

All students participated in a beginning- and end-of-term survey. Both surveys assessed students' opinions on 16 items that corresponded to the objectives and content of the LLMs using a 5-point Likert-like scale, with "I" corresponding to "strongly disagree" and "5" to "strongly agree." Means scores were calculated for both the Module and Non-Module groups. Subsequently, paired-samples $t$-tests via SPSS Version 23 were implemented to determine if statistically significant differences were found between the means scores in the beginning- and end-of-term survey items for each respective group. Effect size values were calculated for only those scores that resulted as statistically significant. Independent samples $t$-tests were utilized to determine if there were statistically significant differences in the mean scores between the Module and Non-Module groups on the end-ofterm ratings.

Along with the information explained above, the end-of-term survey included open-ended questions that asked students to provide their perceptions of the overarching lessons they gleaned from the class. These open-ended items were only included in the end-of-term survey because they asked students to reflect upon the semester and provide their insights of the significant learning that took place. These responses were analyzed using thematic analysis, a method "for identifying, analyzing, and reporting patterns (themes) within data” (Braun \& Clark, 2006, p. 79), which allows researchers to "encod[e] qualitative information" (Boyatzis, 1998, p. vii). This methodology requires researchers to familiarize themselves with the qualitative data, create initial codes, search for and label themes, and analyze the data within the parameters of those themes (Braun \& Clark, 2006).

\section{The Language Learning Modules (LLMs)}

The 31 students in the Module group participated in four pedagogical interventions - the LLMs - whereas the 31 students in the Non-Module group did not. Besides the presence or absence of this intervention, all content, pedagogical techniques, and materials were the same for both Module and Non-Module groups in each respective language course. Table I displays further information regarding the topics of the LLMs, the learning objectives, sample activities and questions, and when they were utilized in the 16-week term. ${ }^{2}$ 


\begin{tabular}{|c|c|c|}
\hline $\begin{array}{l}\text { Module and } \\
\text { week }\end{array}$ & Learning objectives & Sample homework activities or discussion questions (slightly modified) \\
\hline $\begin{array}{l}\text { Module I: } \\
\text { How can I study } \\
\text { effectively for a } \\
\text { language course? } \\
\text { Week } 3\end{array}$ & $\begin{array}{l}\text { I. Gain awareness of self-regulating, } \\
\text { metacognitive, and metalinguistic } \\
\text { strategies. } \\
\text { 2. Establish individualized goals for the } \\
\text { term. } \\
\text { 3. Reflect on the role of the affective } \\
\text { filter and develop techniques to reduce } \\
\text { anxiety in the L2 classroom. }\end{array}$ & $\begin{array}{l}\text { I. Primer question:Write three goals you have for this course and describe how you } \\
\text { will achieve them. } \\
\text { 2. Read information on metacognitive and metalinguistic strategies by Oxford } \\
\text { ( } 201 \mathrm{I} / 20 \mathrm{I} \text { ). What study or self-regulation techniques will you use in each of the four } \\
\text { dimensions as identified by Oxford? } \\
\text { 3. Post-reading reflection:Write } 200-250 \text { words in English on how you will work on } \\
\text { becoming a self-regulated learner.What new information gleaned from this reading will } \\
\text { you implement throughout the semester to perform well and accomplish your three } \\
\text { goals in our Spanish class? How might these strategies apply to your other classes as } \\
\text { well? } \\
\text { 4. After watching the video on the affective filter, describe what it is, and how you can } \\
\text { lower it. }\end{array}$ \\
\hline $\begin{array}{l}\text { Module 2: } \\
\text { What is oral } \\
\text { proficiency? } \\
\text { Week } 6\end{array}$ & $\begin{array}{l}\text { I. Analyze the ACTFL oral proficiency } \\
\text { scale. } \\
\text { 2. Reflect on current L2 oral proficiency. } \\
\text { 3. Create an action plan on how to } \\
\text { progress to next sub-level on the } \\
\text { ACTFL oral proficiency scale. }\end{array}$ & $\begin{array}{l}\text { I. Read a brief explanation of oral proficiency and analyze the ACTFL oral proficiency } \\
\text { scale. } \\
\text { 2. What are your strengths and weaknesses when speaking in the language? } \\
\text { 3.What proficiency level do you think you are? Justify this self-assessment by using the } \\
\text { ACTFL oral proficiency scale. } \\
\text { 4. How can you progress in oral proficiency? What will you need to bear in mind? } \\
\text { Create a plan. }\end{array}$ \\
\hline $\begin{array}{l}\text { Module 3: } \\
\text { What are the } \\
\text { cognitive benefits } \\
\text { of being bilingual? } \\
\text { Week } 10\end{array}$ & $\begin{array}{l}\text { I. Acquire an understanding of the } \\
\text { cognitive benefits of } L 2 \text { learning. } \\
\text { 2. Investigate and report on studies } \\
\text { or articles that explored the broader } \\
\text { benefits of bilingualism (e.g., profession- } \\
\text { al opportunities). } \\
\text { 3. Reflect on how this knowledge might } \\
\text { change how students think of the role } \\
\text { of the L2 in their lives. }\end{array}$ & $\begin{array}{l}\text { I. Primer question:To you, what does it mean to be bilingual? } \\
\text { 2. Watch a video on bilingualism. Explain how bilinguals have cognitive, social, and emo- } \\
\text { tional advantages. } \\
\text { 3. Read an infographic by the Modern Language Association on the benefits of language } \\
\text { learning throughout one's lifetime. } \\
\text { 4. List two benefits of language learning that you were unaware of before reading. Do } \\
\text { these benefits surprise you? Why or why not? How will you use this information as you } \\
\text { move forward in our class and, more importantly, after our class has concluded? } \\
\text { 5. Synthesize a research article about one of these advantages and report on it to } \\
\text { classmates. }\end{array}$ \\
\hline $\begin{array}{l}\text { Module 4: } \\
\text { What is global } \\
\text { competence and } \\
\text { why is it import- } \\
\text { ant? } \\
\text { Week } 13 / 15\end{array}$ & $\begin{array}{l}\text { I. Explore the meaning of "global com- } \\
\text { petence" and how an L2 plays a role in } \\
\text { acquiring this ability. } \\
\text { 2. Learn about other students' experi- } \\
\text { ences with international education. } \\
\text { 3. Discuss the importance of "empathy" } \\
\text { and how students might apply these } \\
\text { concepts after the class. }\end{array}$ & $\begin{array}{l}\text { I. Primer question: What are the main benefits of studying languages and cultures at } \\
\text { our institution? } \\
\text { 2. Watch a video and answer questions on international education, global competence, } \\
\text { and the importance of empathy. } \\
\text { 3. What type of personal and professional opportunities could arise from international } \\
\text { travel and an enhanced understanding of other cultures? Have you studied abroad? } \\
\text { What were its advantages? } \\
\text { 4. Describe what "empathy" means and why is it important to have empathy for others. } \\
\text { How do these ideas relate to what we have been studying in our class this term? } \\
\text { 5. After reading ACTFL's position statement on global competence, analyze how we } \\
\text { have been working toward global competence in our class this term. } \\
\text { 6. How will you continue to develop as a global competent individual after completing } \\
\text { our class? }\end{array}$ \\
\hline
\end{tabular}

When designing and implementing each module activity, constructivist pedagogy informed our decisions and actions. As Richardson (2003) explained, instructors that employ constructivist pedagogy create student-centered activities based on learners' backgrounds and prior knowledge, provide both directed and serendipitous learning opportunities, allow students to process and challenge the material utilizing their knowledge for enhanced meaning-making, and foster metacognitive awareness (p. 1626). Because constructivist pedagogy aligned closely with the goals of this SoTL action research project, especially as the LLMs were tailor-made based on the data provided by students the previous term, we aimed to develop questions and activities that embodied this pedagogical approach (Table I).

In terms of how the LLMs were administered, each module consisted of a homework assignment that students prepared prior to classes designed as "Module Days." Each module homework activity had a similar structure. First, students answered primer questions to activate their prior knowledge and to make meaning out of the content. Next, they read or watched relevant information to enhance their understanding of the topics. Subsequently, students responded to reflection or forward-thinking questions in which they articulated why this information was useful or how they would apply these concepts or strategies in their lives. At the beginning of each "Module Day," the instructors provided discussion opportunities so students could brainstorm together how they could implement salient concepts relevant to their academic, personal, or professional circumstances. The instructors answered students' questions and provided additional context to inform the conversation if necessary. Approximately 15-20 minutes of class time was spent processing the information in the LLMs. Students turned in their homework for a grade. The content of these interventions was not incorporated in other forms of assessment during this term.

Likewise, the LLMs were implemented strategically during the semester. For example, the instructors delivered the first module on how to effectively study for a language course just 
before the first major exam (week 3). It was inspired by Oxford's (20I I/20I3) S2R Model of L2 learning and contained specific study strategies that students could utilize to better self-regulate and gain agency as they learned the language. The second module was administered close to the time of students' first oral assessment (week 6) and drew from ACTFL's Oral Proficiency Interview scale and descriptors (Swender \& Vicars, 20I2). Students were asked to self-assess their speaking abilities by using ACTFL's criteria and to develop an action plan on how to progress to the next sub-level. The third module on the benefits of bilingualism built on ideas related to oral proficiency (week 10) and incorporated an infographic provided by the Modern Language Association titled "The Benefits of Bilingualism." Students were introduced to a variety of new concepts related to bilingualism through a short video and applied this knowledge to investigate news stories on the cognitive and professional benefits of bilingualism. The final module on global competence was placed toward the end of the term (week I3/I5). ${ }^{3}$ This module incorporated ACTFL (20I4)'s "Global Competence Position Statement," defined as the "ability to communicate with respect and cultural understanding in more than one language" and a key skill in today's economic and diplomatic sectors needed for effective problem-solving and interaction with diverse communities (para. I). This inclusion of global competence in the LLMs aimed to convey to students how their language course fit into the more altruistic goal of developing the ability to empathetically and respectfully communicate with a variety of individuals.

\section{RESULTS}

To respond to the research question - to what extent did the module interventions impact students' opinions of metacognitive strategies, metalinguistic awareness, and L2 relevance?-we considered the results from the quantitative and qualitative analyses. First, paired-samples $t$-tests were performed to determine if there were significant changes over time in students' opinions of the 16 statements that related to the LLMs. Tables 2 and 3 display these results. For the Module group (Table 2), Items I, 2,
$4,10,11,12$, and 13 were selected as having a statistically significant difference in mean scores from the beginning to the end of the term. For the Non-Module group (Table 3), Items I, 2, 3, 4, $5,8,10$, and 12 were selected as having a statistically significant difference in mean scores from the beginning to the end of the term. More specifically, when comparing the number of items selected as statistically significant along with the corresponding effect sizes, the Module group rated Items 10-13-which corresponded to Module 3 (cognitive benefits of bilingualism) and Module 4 (global competence) - differently than the Non-Module group. In other words, the Module groups' ratings of these statements showed more change from the beginning to the end of the course. Additionally, all mean ratings of Items I-5-which pertained to Module I (how to effectively study and prepare for a language course) - increased over time for both groups, indicating that upon completing the term students expressed more confidence in knowing how to study for their French or Spanish class. Yet, the Non-Module group (Table 3) displayed more statistically significant change in their evaluation of Items I-5 when compared to the Module group (Table 2).

Another noteworthy finding, but not in terms of statistical significance, was with Item 16 "In order to effectively communicate with a native speaker (NS), I don't need to be familiar with their culture." When comparing how the mean scores changed from the beginning to the end of the term, the Module group's mean decreased -.03 to $M=1.8 \mathrm{I}$, which indicated that this group, overall, slightly changed their opinion of this statement over time (Table 2).Yet, the Non-Module group's mean score increased from the beginning to the end of the course +.16 to $M=1.74$ (Table $3)$. Both groups, however, expressed disagreement with this statement on each of the surveys, suggesting that learners already grasped that cultural competence was important when interacting with NSs.

\begin{tabular}{|c|c|c|c|c|c|c|c|}
\hline \multirow[t]{2}{*}{ Survey Item } & \multicolumn{2}{|c|}{$\begin{array}{c}\text { Beginning of } \\
\text { term }\end{array}$} & \multicolumn{2}{|c|}{$\begin{array}{l}\text { End of } \\
\text { term }\end{array}$} & \multirow[b]{2}{*}{$t$} & \multirow[b]{2}{*}{$p$} & \multirow[b]{2}{*}{$r^{2}$} \\
\hline & M & SD & M & SD & & & \\
\hline \multicolumn{8}{|l|}{ Items related to Module I } \\
\hline I.I know how to effectively study and practice grammar in order to master concepts. & 3.77 & .99 & 4.19 & .79 & -2.28 & .030 & .15 \\
\hline 2. In a given week, I know how to study for this course in order to be successful. & 3.81 & .91 & 4.23 & .62 & -2.44 & .021 & .17 \\
\hline 3. I know how to effectively study and practice vocabulary in order to master the concepts. & 3.97 & .84 & 4.35 & .72 & -1.49 & .147 & -- \\
\hline 4. I feel confident in knowing how to effectively prepare for assessments (quizzes, tests, etc.). & 3.52 & 1.00 & 4.10 & .79 & -2.97 & .006 & .23 \\
\hline 5. Taking charge of my own learning is vital for my progress as a language student. & 4.42 & .77 & 4.55 & .72 & -.81 & .423 & -- \\
\hline \multicolumn{8}{|l|}{ Items related to Module 2} \\
\hline 6. I understand that becoming a proficient speaker is a difficult and long process. & 4.55 & 1.12 & 4.65 & .84 & -.59 & .557 & -- \\
\hline 7.I will be disappointed if I don't reach perfect oral proficiency by the end of my language studies. & 2.36 & 1.17 & 2.48 & 1.12 & -.56 & .580 & -- \\
\hline 8. I am willing to speak up in class in the target language even though I make mistakes. & 3.55 & 1.03 & 3.87 & .96 & -1.83 & .077 & -- \\
\hline \multicolumn{8}{|l|}{ Items related to Module 3} \\
\hline 9. Most people in the world speak only one language. & 1.97 & 1.05 & 1.74 & .86 & 1.16 & .256 & -- \\
\hline 10. Learning a language will help me think and problem-solve better. & 3.97 & .95 & 4.35 & .71 & -2.83 & .008 & .21 \\
\hline II. Only those who completely master two languages can be considered bilingual. & 3.16 & 1.07 & 2.61 & 1.12 & 2.20 & .035 & .14 \\
\hline 12. Learning a language will keep me healthier as I age. & 3.23 & 1.02 & 4.26 & .63 & -5.85 & .000 & .53 \\
\hline \multicolumn{8}{|l|}{ Items related to Module 4} \\
\hline 13. Learning a language will make me more empathetic. & 3.81 & .95 & 4.39 & .62 & -3.82 & .001 & .33 \\
\hline I4. To achieve my future goals, I only need to know and speak English. & 2.35 & 1.08 & 2.32 & 1.01 & .15 & .882 & -- \\
\hline I5. I am eager to know about other cultures and people who are different than me. & 4.39 & .72 & 4.49 & .68 & -.90 & .374 & -- \\
\hline 16. In order to effectively communicate with a NS, I don't need to be familiar with their culture. & 1.84 & .82 & 1.81 & .98 & .14 & .887 & -- \\
\hline
\end{tabular}




\begin{tabular}{|c|c|c|c|c|c|c|c|}
\hline \multirow[t]{2}{*}{ Survey Item } & \multicolumn{2}{|c|}{$\begin{array}{c}\text { Beginning of } \\
\text { term }\end{array}$} & \multicolumn{2}{|c|}{$\begin{array}{c}\text { End of } \\
\text { term }\end{array}$} & \multirow[b]{2}{*}{$t$} & \multirow[b]{2}{*}{$p$} & \multirow[b]{2}{*}{$\mathbf{r}^{2}$} \\
\hline & $\mathbf{M}$ & SD & M & SD & & & \\
\hline \multicolumn{8}{|l|}{ Items related to Module I } \\
\hline 1.I know how to effectively study and practice grammar in order to master concepts. & 3.84 & .93 & 4.32 & .65 & -2.40 & .023 & .16 \\
\hline 2. In a given week, I know how to study for this course in order to be successful. & 4.00 & .68 & 4.45 & .62 & -2.96 & .006 & .22 \\
\hline 3. I know how to effectively study and practice vocabulary in order to master the concepts. & 3.87 & .76 & 4.45 & .51 & -4.49 & .000 & .40 \\
\hline 4.I feel confident in knowing how to effectively prepare for assessments (quizzes, tests, etc.). & 3.74 & .89 & 4.32 & .79 & -3.65 & .001 & .31 \\
\hline 5. Taking charge of my own learning is vital for my progress as a language student. & 4.58 & .62 & 4.84 & .37 & -2.11 & .043 & .13 \\
\hline \multicolumn{8}{|l|}{ Items related to Module 2} \\
\hline 6. I understand that becoming a proficient speaker is a difficult and long process. & 4.81 & .48 & 4.81 & .40 & .000 & 1.000 & -- \\
\hline 7.I will be disappointed if I don't reach perfect oral proficiency by the end of my language studies. & 2.10 & 1.04 & 2.41 & 1.12 & -1.83 & .077 & -- \\
\hline 8. I am willing to speak up in class in the target language even though I make mistakes. & 3.55 & .96 & 4.26 & .96 & -4.38 & .000 & .39 \\
\hline \multicolumn{8}{|l|}{ Items related to Module 3} \\
\hline 9. Most people in the world speak only one language. & 2.29 & .86 & 2.06 & .93 & 1.23 & .229 & -- \\
\hline 10. Learning a language will help me think and problem-solve better. & 3.84 & .90 & 4.19 & .83 & -2.62 & .014 & .19 \\
\hline 11. Only those who completely master two languages can be considered bilingual. & 3.61 & 1.12 & 3.39 & 1.18 & 1.05 & .304 & -- \\
\hline 12. Learning a language will keep me healthier as I age. & 3.32 & 1.08 & 3.74 & 1.00 & -2.64 & .013 & .19 \\
\hline \multicolumn{8}{|l|}{ Items related to Module 4} \\
\hline 13. Learning a language will make me more empathetic. & 4.00 & .93 & 4.19 & .87 & -1.44 & .161 & -- \\
\hline 14. To achieve my future goals, I only need to know and speak English. & 2.71 & 1.19 & 2.68 & 1.05 & .197 & .845 & -- \\
\hline 15. I am eager to know about other cultures and people who are dif & 4.48 & .77 & 4.65 & .66 & -1.22 & .231 & -- \\
\hline 16. In ord & & & 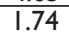 & .96 & & & \\
\hline
\end{tabular}

Additionally, independent-samples $t$-tests were conducted to compare the mean ratings for the 16 end-of-course survey items between the Module and Non-Module groups. The analyses selected two survey items as statistically significant. First, there was a significant difference in the mean scores of Item II for the Module group $(M=2.61, S D=1.12)$ and Non-Module group $(M$ $=3.39, S D=1.17) ; t(60)=-2.66, p=.01$, with a medium effect size of $r^{2}=.13$. This indicates that the Module group more strongly disagreed with the statement "Only those who completely master two languages can be considered bilingual" when compared to the Non-Module group. Likewise, there was a significant difference in the mean scores of Item 12 for the Module group $(M=4.26$, $S D=.63)$ and Non-Module group $(M=3.74, S D=1.00) ; t(60)$ $=2.432, p=.02$, with a medium effect size, $r^{2}=.10$. This finding reveals that the Module group more strongly agreed with the statement "Learning a language will keep me healthier as I age" when compared to the Non-Module group. Items II and I 2 are both connected to Module 3. No other significant differences were found in the mean ratings on the end-of-term survey items between the groups.
Furthermore, to respond to the research question and to complement the quantitative analyses, students' open-ended responses from the end-of-term survey were analyzed qualitatively. Given that this type of data can enhance quantitative analyses and "offer a far greater richness, adding more depth and color to the data than answers to closed-response items," the responses to two open-ended questions were considered in this investigation (Brown, 2009, p. 205). Table 4 presents the thematic analysis results for the question "What in particular did you learn this semester? How did you grow as a student?." Looking at the distribution of responses, $60 / 106(56.6 \%)$ were categorized as "Skills and Knowledge," 27/106 (25.5\%) pertained to "Metacognitive and Metalinguistic Awareness," and 19/106 (17.9\%) corresponded to the theme of "Attitudinal Changes." There are several similarities between the Module and Non-Module groups' responses regarding the distribution in each category and the content within two of the three themes. For instance, within "Skills and Knowledge" both groups expressed that cultural knowledge, grammatical structures, and speaking were areas in which they most grew. Also, within "Attitudinal Changes" both groups cited their confidence in the language developed during the course.

\begin{tabular}{|c|c|c|}
\hline & Module Group & Non-Module Group \\
\hline $\begin{array}{l}\text { Skills and } \\
\text { Knowledge }\end{array}$ & $\begin{array}{l}n=30 \\
\text { Cultural knowledge (8) } \\
\text { L2 grammatical structures (8) } \\
\text { L2 speaking (7) } \\
\text { L2 cognition and processing (4) } \\
\text { L2 vocabulary (3) }\end{array}$ & $\begin{array}{l}n=30 \\
\text { Cultural knowledge (9) } \\
\text { L2 speaking (7) } \\
\text { L2 grammatical structures (5) } \\
\text { L2 writing (2) } \\
\text { Perseverance and flexibility (2) } \\
\text { Collaboration skills }(I) \\
\text { Knowledge of NS communities (I) } \\
\text { L1 skills }(I) \\
\text { L2 comprehension (I) } \\
\text { L2 vocabulary }(I)\end{array}$ \\
\hline $\begin{array}{l}\text { Metacognitive } \\
\text { and } \\
\text { Metalinguistic } \\
\text { Awareness }\end{array}$ & $\begin{array}{l}n=14 \\
\text { Awareness of L2 learning (5) } \\
\text { Awareness of benefits of risk-taking and overcoming anxiety (4) } \\
\text { Translating metacognitive skills to other classes (3) } \\
\text { Study strategies and preparation (2) }\end{array}$ & $\begin{array}{l}n=13 \\
\text { Awareness of personal learning styles (4) } \\
\text { Study strategies and preparation (4) } \\
\text { Awareness of benefits of risk-taking and overcoming anxiety (3) } \\
\text { Awareness of L2 grammar (I) } \\
\text { Awareness of L2 learning (I) }\end{array}$ \\
\hline $\begin{array}{l}\text { Attitudinal } \\
\text { Changes }\end{array}$ & \begin{tabular}{|l}
$n=10$ \\
Increased L2 confidence (7) \\
Value of L2 learning (2) \\
Newfound interest in studying abroad (I)
\end{tabular} & $\begin{array}{l}n=9 \\
\text { Increased L2 confidence (8) } \\
\text { Empathy for L2 learners (I) }\end{array}$ \\
\hline
\end{tabular}


While students in both groups responded in similar ways, there are some important differences to highlight in the thematic analysis displayed in Table 4. Within "Metacognitive and Metalinguistic Awareness," the Module group $(n=14)$ cited more frequently that they learned about topics related to metalinguistic awareness when compared to the Non-Module group $(n=$ 13). Additionally, some students expressed that they realized that these metacognitive techniques could translate to other classes $(n=3)$; this sub-theme was absent from the Non-Module group $(n=0)$. Finally, students in the Module group explicitly communicated that they learned about the value of language learning ( $n$ = 5), while this sub-theme was not expressed amongst students from the Non-Module group within "Attitudinal Changes" $(n=0)$.

The results of the thematic analysis from the second openended question- "What will you take away from this course other than enhanced [L2] abilities?"- -are shown in Table 5. Depending on the length of responses, some students offered more than one "takeaway," which is reflected in the number of answers in each group. The Module group provided more responses $(n=50)$ when compared to the Non-Module group $(n=43)$, and the two groups differed in terms of the content of the lessons learned. With respect to commonalities, both the Module and Non-Module groups expressed that cultural awareness, time management skills, greater confidence, and an increased ability to communicate in the language were some other takeaways from their language learning experience. Regarding divergences of themes between the groups, the Module group overwhelmingly rated global competence as the most impactful lesson from the course $(n=18)$, while the Non-Module group had fewer outcomes listed that were categorized as those skills that related to global competence $(n=5)$. Another notable trend in the Module group's responses pertains to "awareness of language learning." This is the second most frequently cited item by this group $(n=7)$, whereas only one mention of this theme was found in the Non-Module group. Additionally, two students from the Module group expressed that they were interested in continuing learning French or Spanish. One student mentioned the LLMs by name as the major takeaway from the course, which was understandably absent from the Non-Module group's answers.

With regard to trends in the Non-Module group data (Table 5 ), students most frequently cited that they will leave the course with an improved sense of how to study and prepare for their language course $(n=8)$ as well as an enhanced sense of cultural awareness $(n=7)$. Even though the survey question prompted students to think beyond honing specific language abilities, the Non-Module group nonetheless commented that improvements in language skills was a major outcome of the course $(n=6)$.

\section{DISCUSSION}

This SoTL study targeted how the pedagogical intervention project, the LLMs, impacted students' opinions of metacognitive strategies and metalinguistic awareness, and their ability to see the relevance of studying an L2. Regarding students' opinions of metacognitive strategies and metalinguistic awareness, the analyses show that both groups, without prompting, stated that they would remember the metacognitive skills learned in the course and were more aware of how study strategies fostered their language learning. Yet, when examining the content under these themes, some differences between the groups come to light. Module I focused on how students could use strategies to self-regulate their learning environments, their anxiety in these environments, how they used their time outside of class in order maximize the L2 experience, and provided them with examples of how they could take ownership of their learning. The Module students had not considered many of these elements as part of the language learning process beforehand. For instance, one of these student commented,"I learned a lot about the way that I personally learn and ways that I can use that knowledge to study more effectively. My confidence has grown a lot and willingness to speak up even if I am not sure I have the right answers." Additionally, the analyses reveal that students from the Module group appeared to grasp how the study strategies and concepts related to self-regulation applied to other academic environments along with their present one, whereas the Non-Module group exclusively focused on metacognitive strategies for their immediate language learning context. We see this borne out in some of the Module students' comments on the end-of-term survey. For instance, one Module participant stated:"I think I also improved as a student in terms of my study skills. I think I have more effective methods I can apply to all my classes." Another student described how s/he reorganized time outside of class and how this concept could apply to other contexts: "I think I will be able to incorporate the skills I learned with time management in this class into my everyday life." Even though Module I did not appear to influence Module students' ratings on how well they rated their preparation and study strategies on the survey items related to Module I (Table 2), for some Module students this intervention did seem to give them a broader understanding of the fundamental skills and concepts related to metacognition and what students themselves could do to progress toward being a self-regulated learner in a wider array of contexts.

Furthermore, the Module group appeared to possess a deeper understanding and appreciation of language learning itself by the end of the course. For instance, one Module student showed a greater awareness of how affective variables could influence language learning: "I think one thing I will take away is the idea of how confidence in my skills in a subject will lead

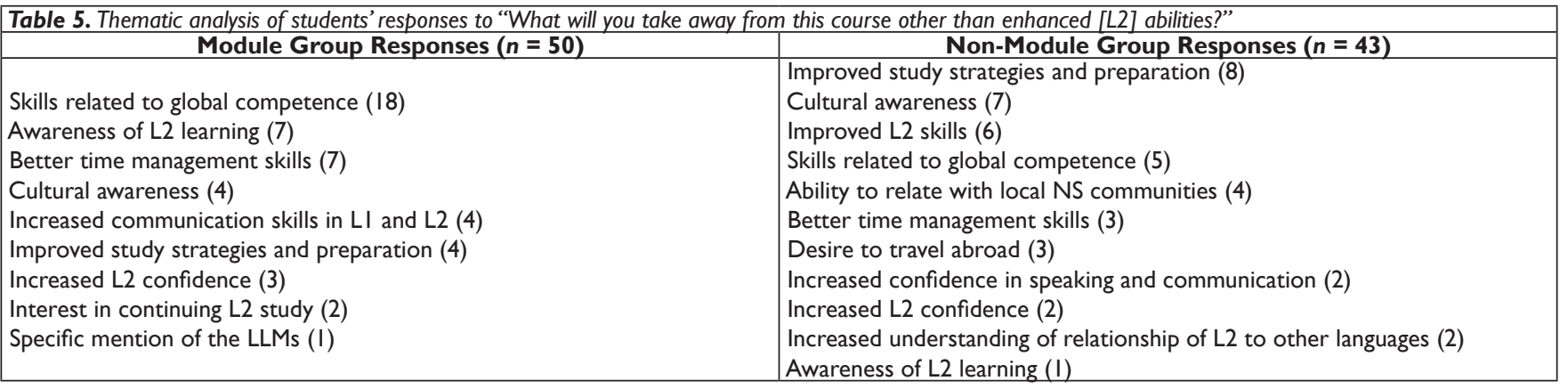


me to actually be able to learn more." Other Module students commented: "I learned a lot about learning language in general outside of [the L2] and how important it is" and "[i]n terms of growing as a student, I now understand a lot more about how I learn, whether it be in [the L2] or not[.] I am also just more confident in my abilities as a student, which I didn't think would happen.' Trends in the Non-Module groups' comments seem to indicate that they became more aware of their growth in L2 confidence and skills, how the language operates, and effective study habits for language classes, which are undoubtedly beneficial insights related to metacognitive and metalinguistic understanding. Yet, again, these Module students developed more in their ability to consider the larger picture beyond their individual experience in this academic setting, and students had the vocabulary and knowledge to draw from to articulate this learning. As Pintrich (2002) contended:"[o]ne of the most important aspects of teaching for metacognitive knowledge is the explicit labeling of it for students" (p. 223). Perhaps it was this "explicit labeling" through participating in Module I that allowed students to cite the broader applications of metacognition as well as its value in their overall learning.

The greatest difference between the Module and Non-Module groups was seen in how students did or did not find meaning and relevance in language learning for their personal trajectories. We included Module 3 (cognitive benefits of bilingualism) and Module 4 (global competence) precisely to explore if possessing this knowledge could positively impact students' opinions on language learning and provide them with relevant, and accurate, information on the benefits and features of multilingualism. In other words, the purpose of these modules was to explicitly point out to students the relevance of studying an $L 2$ with the hope of instilling in them a heightened sense of appreciation of other languages and a renewed sense of purpose for taking the course beyond simply completing the university requirement. Thus, Modules 3 and 4 emphasized why language learning is critical in today's globalized world; more precise notions of what it means to be "bilingual;" how bilingualism is researched and its role in a variety of professional fields; how knowing another language and using it with empathy could benefit them throughout their lifetime; and the importance of speaking languages other than English with respect and cultural sensitivity. The results from the 16-item survey-specifically Items I0-13 and, to a certain degree, Item 16 -indicate that the Module students understood the concepts included in Modules 3 and 4, and grasped the relevance of L2 study. When the survey findings are considered in concert with the results of the thematic analyses, the Module students clearly expressed that global competence resonated with them. Additionally, we should underscore that all 62 students were encouraged to challenge cultural stereotypes of both Francophone and Hispanic cultures through regular activities that focused on these cultures; however, only the Module students had formal training on global competence and time in class to process their understanding of it along with these cultural exercises. The Module students showed their understanding of global competence by stating that they discovered that "there [is] more to learning a language than just knowing another language" and an "understanding of culture [...] will help me communicate with others." In addition, students found value and relevance in the concept by acknowledging that global competence "will help me to navigate different cultures and make new friends" and it "[will help me in] my future professional world." They not only understood that global competence is a sought-after ability, but also that proficiency alone was not enough if students were going to interact successfully with NSs in the future.

Moreover, the LLMs gave students a new perspective of language learning itself. For example, two students in the Module class commented at the end of the course that they reconsidered how the language applied to them and discovered its value. Specifically, one stated:"I will definitely take away an understanding for how important knowing different language [sic] can be and what a good skill it is to have. While I never considered taking any other [L2] classes, I am now considering continuing with my language learning." The other Module student affirmed that s/he grew in terms of appreciating the applicability of languages outside of an academic context: "I learned more about the value of learning a language - a lot of our classes, especially from high school, weren't too applicable to daily life and built up sets of arbitrary skills, but I learned the value of language learning and its direct applications to the real world in this course." These types of comments were absent from the Non-Module group's responses. Considering that most students had ample previous experience with French or Spanish in an academic context, comments like these lead us to the conclusion that Module 3 and Module 4 were especially impactful and that we should continue including this content in our language courses.

While the quantitative and qualitative data analyzed in the present study appear to support the use of some of the LLMs in intermediate L2 post-secondary courses in the United States, it is important to note the limitations of this study as well as possible recommendations for those who are interested in implementing this type of intervention. First, given that this investigation included a relatively small sample size of students from four classes at one university does not make it possible to guarantee the generalizability of the findings to all language learners in all learning contexts. We would like to encourage other researchers to examine how these pedagogical inventions are received in their classrooms and by their learners in order to corroborate, or not, our findings. Secondly, we recognize that the quantitative results do not seem to show that the content of Module I made a difference over time regarding how students in the Module group selfrated their ability to regulate their own learning in the course. It is also important to state that we still trained Non-Module students on how to prepare and study for language classes, but just not through the structured activities of Module I. Perhaps this could partially account for why the quantitative results did not reveal any revelatory gains by the Module group. However, we contend that it is critical to pair these analyses with the qualitative results in order to fully assess the impact of Module I. It is also possible that after some revising of the content and activities, Module I could foster greater improvements of students' metacognitive and metalinguistic awareness. As far as Module 2 on oral proficiency is concerned, neither the quantitative nor the qualitative findings suggest that this module made a notable impact on the Module students. By simply participating in the intermediate French or Spanish class itself, it appears that students in both groups made similar gains in self-reported L2 confidence and speaking abilities by the end of the term.

Although not included in the present SoTL investigation, we recommend that researchers interested in conducting similar studies include measures of language production-e.g., oral proficiency, grammatical competence-and affective variables 
that can influence language acquisition-e.g., L2 motivation, confidence, and anxiety - in order to ascertain how the LLMs might impact these elements as well. Of course, we also highly encourage instructors both in languages and in other disciplines to use action research similarly to determine what type of intervention modules to implement with students. Finally, with respect to future directions of improving the LLMs themselves, moving toward a model where the content of the LLMs is included on summative assessments would further stress the significance of this information to students. We also believe that dedicating more time in class to the LLMs would enhance their execution as it would allow for a deeper processing of the concepts.

\section{CONCLUSION}

Looking at the overall success of this intervention module project, we found that Modules 3 and 4, and to some extent Module I, positively impacted students' self-reported growth in metacognitive skills and metalinguistic awareness, and in their ability to find relevance in language learning. Even with its limitations, this intervention project contributes to critical advocacy efforts in the field, such as those strongly endorsed by Moeller and Abbott (2018, p. I2), through deliberately and directly educating students on how to study a language, the value of L2 study, and the need for multilingualism, multiculturalism, and global competence. We believe that incorporating this type of information systematically in $\mathrm{K}-\mathrm{I} 2$ and post-secondary language programs has tremendous potential to enrich the academic, personal, and professional lives of English-dominant millennial learners. Likewise, the LLMs can be applied in a variety of L2 contexts, such as different levels of schooling and different levels of ability. Given the current climate in which hundreds of post-secondary language programs in the United States have been eliminated between 2013 and 2016 (Johnson, 2019), and where only $20 \%$ of school-aged children are required to take a language as part of their $\mathrm{K}-\mathrm{I} 2$ studies (American Councils for International Education, 20I7), endeavors such as the LLMs are vital today for creating globally competent citizens that are devoted to learning about different languages and cultures. If language instructors are explicitly drawing students' attention to the value and relevance of language education now, it is possible that these same learners could become the advocates, citizens, and policymakers who promote language education for all in the future.

\section{NOTES}

I.We prefer to use "second language" (L2) or simply "language" interchangeably in the present article, although we acknowledge that other terms-such as "foreign language" or "target language"could apply.

2. If readers are interested in viewing the LLMs in their entirety, please contact the authors via email.

3. It was not possible to conduct Module 4 during the same week in the French (week I3) and Spanish (week I5) classes due to scheduling conflicts.

4. For the purposes of readability, we grouped the survey items by Module. The number associated with each statement in Tables 2 and 3 do not correspond to the order of the survey items, as they were randomized. 


\section{REFERENCES}

American Council on the Teaching of Foreign Languages. (20/4) Global Competence Position Statement. Retrieved from https://www.actfl.org/news/position-statements/global-competence-position-statement

American Councils for International Education (2017). The national K-I2 enrollment survey report. Retrieved from https://www.americancouncils.org/sites/default/files/FLE-report-June I7.pdf

Bessy, M., \& Knouse, S. (20I7). From high school to college: How to improve language learning transition. Roundtable presentation at the Annual Convention of the American Council on the Teaching of Foreign Languages (ACTFL), Nashville, TN, November 2017.

Boyatzis, R.E. (1998). Transforming qualitative information:Thematic analysis and code development. Thousand Oaks, London, \& New Delhi: SAGE Publications.

Braun,V., \& Clarke,V. (2006). Using thematic analysis in psychology. Qualitative Research in Psychology, 3, 77-101.

Brown, J. D. (2009). Open-response items in questionnaires. In J. Heigham \& R.A. Croker (Eds.), Qualitative research in applied linguistics: A practical introduction (pp. 200-219). Basingstoke: Palgrave Macmillan.

Brown, S., \& Larson-Hall, J. (20I5). Second language acquisition myths:Applying second language research to classroom teaching. Ann Arbor: University of Michigan Press.

Buckner, M. M., \& Strawser, M. G. (2016). Millennials and the paralysis of choice: reigniting the purpose of higher education. Communication Education, 65(3), 36I-363.

Busse, V., \& Walter, C. (20I3). Foreign language learning motivation in higher education:A longitudinal study of motivational changes and their causes. The Modern Language Journal, 97(2), 435-456.

Coleman, J. A. (2009). Why the British do not learn languages: Myths and motivation in the United Kingdom. Language Learning Journal, 37( I), I I I- 27.

de Bot, K. (2007). Language teaching in a changing world. The Modern Language Journal, 9 I (2), 274-276.

Donitsa-Schmidt, S., Inbar, O., \& Shohamy, E. (2004). The effects of teaching spoken Arabic on students' attitudes and motivation in Israel. Modern Language Journal, 88(2), 217-228.

Fedoruk, L. (20I7). Ethics in the scholarship of teaching and learning: Key principles and strategies for ethical practice. Taylor Institute for Teaching and Learning Guide Series. Calgary,AB: Taylor Institute for Teaching and Learning at the University of Calgary. www.ucalgary.ca/taylorinstitute/guides
Goh, C. (2008). Metacognitive instruction for second language listening development: Theory, practice and research implications. RELC Journal, 39(2), I88-2 I 3.

Johnson, S. (2019, January 22). Colleges lose a 'stunning' 65I foreign-language programs in 3 years. The Chronical of Higher Education. Retrieved from https://www.chronicle.com/article/Colleges-Lose-a-Stunning-/245526

Modern Language Association. Benefits of Language Learning. [Infographic]. Retrieved from https://www.mla.org/Resources/Advocacy/Infographics/Infographic-Benefits-of-Language-Learning

Moeller,A. J., \& Abbott, M. G. (20।8). Creating a new normal: Language education for all. Foreign Language Annals, 5 I ( I), I 2-23.

Oxford, R.L. (20I3). Teaching and researching language learning strategies. New York: Routledge. (Original work published 20II).

Pintrich, P. R. (2002). The role of metacognitive knowledge in learning, teaching, and assessing. Theory into Practice, 4I, 219 225.

Pratt, C. \& Grieve, R. (1984). The development of metalinguistic awareness: An introduction. In W. Tunmer, C. Pratt, \& M. Herriman (Eds.). Metalinguistic awareness in children: Theory, research, and implications (pp. 2-35). New York, NY: Springer.

Richardson, V. (2003). Constructivist pedagogy. Teachers College Record, 105(9), 1623-1640.

Rivera-Mills, S.V., \& Plonsky, L. (2007). Empowering students with language learning strategies: A critical review of current issues. Foreign Language Annals, 40(3), 535-548.

Swender, E., \& Vicars, R. (Eds). (20I2). Oral Proficiency Interview tester training manual.Alexandria,VA:ACTFL.

Thompson, D. R. (20I2). Promoting metacognitive skills in intermediate Spanish: Report of a classroom research project. Foreign Language Annals, 45(3), 447-462.

Tseng, W., Dörnyei, Z., \& Schmitt, N. (2006). A new approach to assessing strategic learning:The case of self-regulation in vocabulary acquisition. Applied Linguistics, 27(I), 78- 102.

Zimmerman, B. J. (2002). Becoming a self-regulated learner: An overview. Theory into Practice, 4I, 64-72. 